\title{
Preface: integrating historical ecology and ecological modeling
}

\author{
Urs Gimmi • Harald Bugmann
}

Received: 14 March 2013/Accepted: 19 March 2013/Published online: 27 March 2013

(C) Springer Science+Business Media Dordrecht 2013

There is increasing consensus that not only the present structure and functioning of ecosystems, but also their response to environmental stressors and management practices is partly a legacy of the system's history (Rhemtulla and Mladenoff 2007). Similarly, there is little dispute that in order to assess the future trajectories of ecosystems, models of some sort need to be employed (e.g., Shugart 1998). Thus, there is a clear interface between the scientific attempts to elucidate the past of ecosystems (historical ecology) and the attempts to project their future dynamics (ecological modeling). However, to date this interface has received relatively little attention in scientific research (cf. Anderson et al. 2006).

On the one hand, historical ecological research usually aims at uncovering past ecosystem dynamics and their drivers, using and combining a large variety of historical data sources (Egan and Howell 2001). A comprehensive understanding of anthropogenic impacts on ecosystems is not only crucial for the accurate interpretation of current ecosystem states,

\section{U. Gimmi ( $\bowtie)$}

Research Unit Landscape Dynamics, Swiss Federal Institute for Forest, Snow and Landscape Research WSL, 8903 Birmensdorf, Switzerland

e-mail: urs.gimmi@wsl.ch

\section{H. Bugmann}

Department of Environmental Systems Science, Forest Ecology, Institute of Terrestrial Ecosystems, ETH Zurich, 8092 Zurich, Switzerland but it also forms the baseline for predictions of their future development, and for more informed ecosystem management (Bürgi and Gimmi 2007). Historical ecologists therefore tend to emphasize the importance of their research for other fields such as ecosystem modeling, but they preferably place such statements in the outlook sections of their papers, often without a clear concept of how such integration should be achieved.

On the other hand, many modeling studies that project the future state and fate of ecosystems are using baseline assumptions regarding current ecosystem states that are not much more than guesswork because they lack a historical consideration. A case in point is the assumption in studies of the future carbon cycle, a topic of eminent scientific, practical and political relevance, that current ecosystem carbon storage is in equilibrium with an assumed constant past climate and a constant past management (e.g., Wolf et al. 2012, and many others). Under most conditions, however, both assumptions are highly questionable, and are acceptable only because reliable and accessible data on past conditions are often absent. Indeed, the quest of modeling studies for appropriate historical data to set up more realistic "spin-up" runs of the models is often futile, as historical data are hardly ever collected and made available with the target variables of modeling studies in mind, unless a close collaboration is sought between modelers and historical ecologists (cf. Gimmi et al. 2009). Still, modelers tend to view historical ecology mainly as a source of 'useful' data while they underestimate the 
complexity and uncertainty inherent in quantitative historical reconstructions of land cover, land-use, and their drivers.

This Special Feature aims to contribute to bridging the common, but inappropriate divide between 'modelers' and 'non-modelers' (in this case, historical ecologist) by presenting examples of the successful combination of historical ecological research and modeling approaches. In disciplines closely related to historical ecology, such as paleoenvironmental sciences (Anderson et al. 2006) and archeology (Johnson et al. 2005), the integration of modeling is established to a larger degree. Anderson et al. (2006) outlined the benefits of linking paleoenvironmental data and models to understand the past and project future environmental changes. They identified different modes how paleoenvironmental studies and models can be interlinked. First, paleo data can be used to validate ecological models and thus to test the reliability of model-based scenario assessments. In turn, models can be used as independent lines of evidence for pre-historical land-use dynamics. Second, models can be used to integrate and synthesize data on past environmental conditions deriving from different disciplines (e.g., historical, archaeological and paleoenvironmental data) and covering different spatial and temporal scales (Johnson et al. 2005). Finally, models can be used to support data interpretation, for example by introducing baseline scenario calculations such as potential natural vegetation, which can be compared against historical data sets (e.g., Gimmi et al. 2009).

We use a similar typology in this Special Feature by considering the potential benefits resulting from the 'cross-pollination' of historical ecology and ecological modeling, as outlined below.

(1) Models may support the interpretation of historical land-use change Models are of great value for identifying the causes of past land-use dynamics. With the help of statistical models, observed past land-use changes can be related to potential abiotic (e.g., climate and topography) and socio-economic driving forces. In this way, models can be used to test hypotheses about key factors driving observed changes in land-use. We present two papers of this type in this Special Feature. Biró et al. (2013) reconstruct the loss of semi-natural grasslands in Hungary after the breakdown of the socialist system and interpret the related drivers using generalized linear models (GLMs), whereas Garbarino et al. (2013) apply path analysis to disentangle the effects of land-use and topography on structural changes in subalpine larch (Larix decidua) forests

(2) Models can be used as independent lines of evidence for historical land-use dynamics The reliability of historical land-use reconstructions can be tested by cross-comparison with other independent sources, or alternatively with the output of land-use models. Henne et al. (2013) combine sedimentary pollen records and dynamic landscape modeling to reconstruct forest vegetation prior to human colonization and its sensitivity to human-induced alteration of fire and browsing regimes for a Mediterranean ecosystem. Their findings provide strong evidence for the potential of historically abundant but vanished vegetation types under the present climate.

(3) Models may support the reconstruction of historical ecosystem dynamics While general landuse patters can be reconstructed based on historical sources, the same sources often do not provide direct information about many aspects of related ecosystem dynamics (e.g., biodiversity or biogeochemical cycles). Here, ecosystem models may serve as a useful tool to uncover these hidden aspects. Gimmi et al. (2013) demonstrate long-term legacy effects of historical litter raking in the soil carbon pools of Swiss forests. They use documentary evidence to determine this historic land-use regime and link their findings with a biogeochemical model in order to evaluate the effects on soil carbon.

(4) Historical data can strongly support the calibration of predictive models Information on past land-use and ecosystem dynamics is essential to make reliable predictions about their future development. Panzacchi et al. (2013) reconstruct traditional migration corridors for Norwegian wild reindeer with the help of archeological findings and compare these routes with current movement behavior that was evaluated based on GPS tracking of the animals. They relate the abandonment of traditional migration routes to the presence of anthropogenic features (roads and tourist infrastructure etc.) and develop a model to predict the impact of additional human disturbance on reindeer migration 


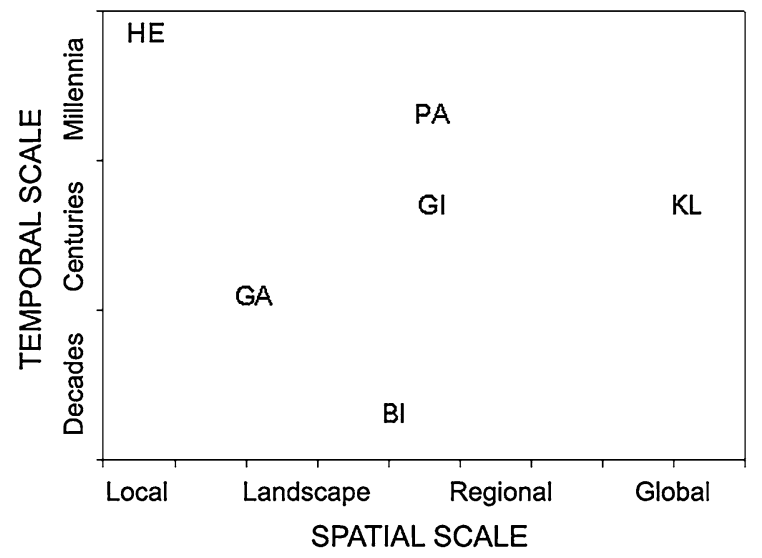

Fig. 1 Spatial and temporal scales covered by the studies presented in this Special Feature (BI Biro et al., GA Garbarino et al., GI Gimmi et al., $H E$ Henne et al., $K L$ Klein Goldewijk et al., $P A$ Panzacchi et al.)

Finally, Klein Goldewijk and Verburg (2013) consider the uncertainties in reconstructions of land-use at continental to global scales. This is a methodological contribution rather than a case study of any specific phenomenon, but it clearly highlights that depending on the purpose of a study that aims at using historical ecological data in a modeling context, different caveats need to be taken into account. They apply source critics (a basic concept in historical research) to evaluate the uncertainties in their modeled land-use dataset. This goes beyond the sensitivity analysis that is often conducted by modelers to assess the importance of model parameters and to determine the key drivers underlying the simulation results. Klein Goldewijk and Verburg (2013) critically and openly discuss the many issues surrounding the quality and reliability of the parameters underlying land-use reconstructions.

The six papers of this Special Feature reveal that the integration of historical ecology and ecological modeling is possible across a wide range of temporal and spatial scales (Fig. 1). They also illustrate that successful interdisciplinary cooperation between historical ecologists and modelers goes far beyond simple data exchange, but requires intensive collaboration based on the mutual interest in each other's research field. This allows the researchers to develop a sense for the realistic possibilities of the other discipline, and to achieve awareness of its inherent limitations.

Acknowledgments This Special Feature derives from a session on 'Integrating Historical Ecology and Ecological
Modeling' at the international conference 'Frontiers in Historical Ecology' held at the Swiss Federal Research Institute for Forest, Snow and Landscape Research WSL in Summer 2011. We wish to express our thanks to Jingle Wu, Editor-in-Chief of Landscape Ecology, for supporting this Special Feature, and to Matthias Bürgi for constructive comments on an earlier version of the manuscript.

\section{References}

Anderson NJ, Bugmann H, Dearing JA, Gaillard M-J (2006) Linking palaeoenvironmental data and models to understand the past and to predict the future. Trends Ecol Evol 21:696-704

Biró M, Czúcz B, Horváth F, Révész A, Csatári B, Molnár Z (2013) Drivers of grassland loss in Hungary during the post-socialist transformation (1987-1999). Landscape Ecol. doi:10.1007/s10980-012-9818-0

Bürgi M, Gimmi U (2007) Three objectives of historical ecology: the case of litter collecting in Central European forests. Landscape Ecol 22:77-87

Egan D, Howell EA (2001) The historical ecology handbook: a restorationist's guide to reference ecosystems. Island Press, Washington, DC

Garbarino M, Lingua E, Weisberg PJ, Bottero A, Meloni F, Motta R (2013) Land-use history and topographic gradients as driving factors of subalpine Larix deciduas forests. Landscape Ecol. doi:10.1007/s10980-012-9792-6

Gimmi U, Wolf A, Bürgi M, Scherstjanoi M, Bugmann H (2009) Quantifying disturbance effects on vegetation carbon pools in mountain forests based on historical data. Reg Environ Chang 9:121-130

Gimmi U, Poulter B, Wolf A, Portner H, Weber P, Bürgi M (2013) Soil carbon pools in Swiss forests show legacy effects from historical forest litter raking. Landscape Ecol. doi:10.1007/s10980-012-9778-4

Henne PD, Elkin C, Colombaroli D, Samartin S, Bugmann H, Heiri O, Tinner W (2013) Impacts of changing climate and land use on vegetation dynamics in a Mediterranean ecosystem: insights from paleoecology and dynamic modeling. Landscape Ecol. doi:10.1007/s10980-012-9782-8

Johnson DC, Kohler TA, Cowan J (2005) Modeling historical ecology, thinking about contemporary systems. Am Anthropol 107:96-107

Klein Goldewijk K, Verburg PH (2013) Uncertainties in globalscale reconstructions of historical land use. Landscape Ecol. doi:10.007/s10980-013-9877-x

Panzacchi M, Van Moorter B, Jordhøy P, Strand O (2013) Learning from the past to predict the future: using archeological findings and GPS data to quantify reindeer sensitivity to anthropogenic disturbance in Norway. Landscape Ecol. doi:10.1007/s10980-012-9793-5

Rhemtulla JM, Mladenoff DJ (2007) Why history matters in ecology. Landscape Ecol 22:1-3

Shugart HH (1998) Terrestrial ecosystems in changing environments. Cambridge University Press, Cambridge

Wolf A, Lazzarotto P, Bugmann H (2012) The relative importance of land use and climatic change in alpine catchments. Clim Chang 111:279-300 